\title{
Subjective discomfort and personality traits of university teachers during the COVID-19 pandemic
}

\author{
Ekaterina Denisova ${ }^{1,{ }^{*}}$, Pavel Ermakov ${ }^{2}$, Irina Skirtach ${ }^{1,2}$ and Viktoria Korkhova ${ }^{1}$ \\ ${ }^{1}$ Don State Technical University, Gagarin Sq., 1, Rostov-on-Don, 344000, Russia \\ ${ }^{2}$ Southern Federal University, B. Sadovaya str., 105/42, Rostov-on-Don, 344006, Russia
}

\begin{abstract}
The current threat of the COVID-19 pandemic has led to the transition to distance (online) education in all educational institutions of the country, including universities. A sudden forced change in the form and structure of education has psychological consequences for all the participants in the educational process. The objective of the study presented was to examine the severity of anxiety, career maladjustment, stress levels, and coping strategies among university teachers during the transition to distance (online) education. The sample comprised 169 individual participants (95 women, $74 \mathrm{men}$ ) aged 25 to 70 years: 119 university teachers of the Rostov region (mean age $=45$ years) and 40 sales specialists as the control group (mean age $=35$ years). The study was conducted online from 04.24.2020 to 06.15.2020. The results indicate a general tendency to increasing stress levels and severity of career maladjustment. university teachers have a higher level of professional motivation and less often complain of feeling unwell and of a decrease in cognitive functions. Less adaptive in terms of stable personality parameters respondents are more likely to experience stress and more prone to manifest unmotivated anxiety. They demonstrate a higher level of career maladjustment and subjective discomfort when using the Internet. The preferred coping strategy is to openly complain about work or general negative feelings. Changes in the dynamic personality characteristics of university teachers during distance education are determined by their stable personality characteristics rather than by their age, which is often mentioned as the main factor for adaptation difficulties.
\end{abstract}

\section{Introduction}

With technological advancements, the digital environment has become an important part of the life context. Education mediated by computer technology cannot be treated as a completely new phenomenon. There is an extensive range of papers on the pros and cons of implementing online (distant, remote) technologies at various levels of education [1-4]. However, current situation of the forced global transition to distance learning during the threat of the COVID-19 pandemic has faced the pedagogical community with the necessity

\footnotetext{
* Corresponding author: denisovakeith@gmail.com
} 
of moving all the existing courses online. Such a sudden change, on the one hand, is accompanied by growing public anxiety in relation to the disease itself, and the uncertainty of the future, on the other. Having virtually no opportunity and time to prepare and adapt to the conditions of modern reality, teachers had to prepare and alter their teaching materials for the online format within one week. Moreover, for many teachers it was necessary not only to master the technical aspects of using the appropriate platforms, but also to deal singlehandedly with the unexpected technical difficulties that arise in the process.

Online format increases the importance of self-organization, competent, and careful redistribution of working and non-working hours. Changes occur not only in the structure of the educational process at the university but also the daily lifestyle of scientific and teaching staff - daily routine, eating, sleeping, working hours and communication with relatives, usual amount of motor activity, level of comfort and the sense of security [5].

The psychological aspects of online (distant, remote) education include the following: determining the age range and personality characteristics of students and teachers who are able to effectively learn using online technologies; students' motivation and professional motivation of faculty members; organization of communication (communicative qualities) in the teacher-student system; features of cognitive functions and building effective behavioral patterns during training using online technologies; various kinds of effects on the psyche of teachers and students [6,7]. Prior research generally confirms that in online learning character traits of both teachers and students are of great importance for maintaining involvement, motivation, and discipline $[8,9]$. Students may have problems such as lack of self-discipline, suitable learning materials, or good learning environments. Researchers note that even in normal circumstances, the online format requires special teaching experience and certain skills, including skills to work with dysfunctional attitudes of students associated with a decrease in their academic motivation [9]. High efficiency of interaction between teachers and students can be achieved only with a conscious and responsible attitude to learning from all the participants in the educational process. Therefore, as a consequence of a disruptive shift of the format the role of the teacher is especially important for maintaining the motivation and performance of students' educational activities [9-11].

The text communication is crucial in online education. The specifics of perceptual learning styles of participants in the educational process using distance technologies have made a significant contribution to the effectiveness of mastering new materials. On the one hand, those who prefer visual forms of processing materials (visual learners) have an advantage. For example, their imaginative (clip) thinking in this case enables them to process information faster compared to those who prefer auditory information (aural learners). On the other hand, a huge number of visual nonverbal keys and emotional feedback to the material just disappear with no physical presence in the classroom. This is especially true when facing technical difficulties such as low quality of video-translation or unstable Internet connection. At the same time, the amount of audio-visual information that needs to be processed greatly increases. The standard forms of communication within 'classroom hours' are supplemented by communication via e-mail or messengers and other means $[3,7]$. That challenges faculty members to keep track of all the additional assignments and to provide quick timely feedback to students.

Current research provides compelling evidence that changes in communication occur at both student-teacher and student-student levels. The absence of face-to-face dialogue is often negatively viewed by both students and the academic community. The lack of personal emotional contacts with classmates can manifest itself in an uncomfortable experience of a feeling of detachment from the group. There may also be an increase in feelings of loneliness and frustration. The lack of real support and mutual assistance may also create additional problems in the process of learning and mastering the material, such as a decrease in enthusiasm and cognitive motivation, etc. [5, 12-13]. Even in traditional forms of education, 
students tend to prefer those teachers with whom they can establish frequent direct contacts using not only personal meetings. They like it better when they can interact by means of telephone conversations, various messengers or e-mail. It is important to remember that students have certain expectations for quick answers, explanations, discussion of arisen organizational difficulties associated with the uncertainty of the situation in terms of the schedule, passing independent work, getting credits, test retakes, certification, and other issues $[12,14]$. Prior research substantiates the belief that with online education the severity of anxiety about the listed problems increases $[4,6,15,16]$. At the same time, the transition to distance learning somewhat blurs the boundaries of contact between students and teachers. Students become more demanding about the getting feedback from the teacher that may also be a source of additional stress.

Thus, in connection with measures to prevent the spread of coronavirus disease (COVID19), the academic community faced not only the need to quickly solve a number of problems, but also an increasing organizational, methodological, pedagogical, and psychological workload. In this regard, the aim of this study is to investigate the severity of anxiety, career maladjustment, stress levels, and coping strategies among university teachers during the transition to distance (online) education provoked by the threat of the COVID-19 pandemic.

\section{Methods}

\subsection{Participants}

The study involved 169 individuals (95 women and 74 men) aged 25 to 70 years. The study was conducted online from 04.24 .2020 to 06.15 .2020 . All respondents voluntarily agreed to participate in the study, were familiarized with its objectives, and notified of further use and publication of the results. The objectives of the study were clearly explained. All the respondents gave their voluntary consent to participate in the study.

The experimental group consisted of university teachers of the Rostov region $(n=119$, mean age $=45$ years), practicing teaching in the format of distance learning. The control group consisted of sales specialists $(n=40$, mean age $=35$ years $)$, whose work activities were also carried out remotely (online) during the period of restrictive measures related to the spread of the new coronavirus disease (COVID-19).

\subsection{Methods and procedure}

To measure personality characteristics of university teachers and sales specialists we used the following questionnaires: the Short Portrait Big Five Questionnaire (BF-10 - Egorova M.S., Parshikova O.V., 2016); the Adaptability Multilevel Personality Questionnaire (MPQA - A.G. Maklakov \& S.V. Chermyanin, 2001); Spielberger State-Trait Anxiety Inventory (modified by Yu.L. Khanin 1995); the questionnaire for the Assessment of career maladjustment (modified by M.A. Dmitrieva, 2000); Norman, Endler, James and Parker Coping Inventory for Stressful Situations (modified by Kryukova T.A., 1992); Express Diagnostics of the Propensity for Unmotivated Anxiety (Boyko V.V., 2000); Express Diagnostics of Stress Levels (Prokhorov A.O., 2000); the scale of Changes in Psychological Boundaries: Reflection of Violation of Boundaries, the questionnaire for the Assessment of Changes in Psychological Boundaries When Using the Internet (Rasskazova E.I., Emelin V.A., Tkhostov A.Sh., 2015).

The study was conducted in the form of single independent between-groups measures (without a preliminary test before the COVID-19 pandemic). The measured personality characteristics were divided into stable and dynamic personality traits. As the most stable 
traits we considered extraversion, agreeableness, conscientiousness, neuroticism, openness to experience (measured using the BF-10 questionnaire), trait anxiety (Spielberger-Khanin test), adaptive potential and adaptiveness (MPQ-A). The dynamic traits were as follows: the level of state anxiety (Spielberger-Khanin test), the severity of career maladjustment (Assessment of career maladjustment), unmotivated anxiety and stress levels (express tests by Boyko and Prokhorov), coping strategies (Coping Inventory for Stressful Situations), as well as the severity of psychological discomfort when using the Internet (Reflection of Violation of Boundaries). This model provides a deeper understanding of the mechanisms underlying changes in the dynamic characteristics of individuals in unstable or new conditions.

Statistical data analysis: Mann-Whitney U-test was used to compare the results of the control and experimental groups; cluster analysis (K-mean clustering) was used to divide the sample by stable personality characteristics; Kruskal-Wallis $\mathrm{H}$ test was used to determine the significance of differences in subgroups. The level of statistical significance, $p$, was taken equal to 0.05 .

\section{Results}

The result presented below show a general tendency to increasing stress levels and severity of career maladjustment. $48 \%$ of respondents showed moderate to high levels of stress. They show signs of general fatigue, anxiety, and discouragement about current life events (Figure $1)$.

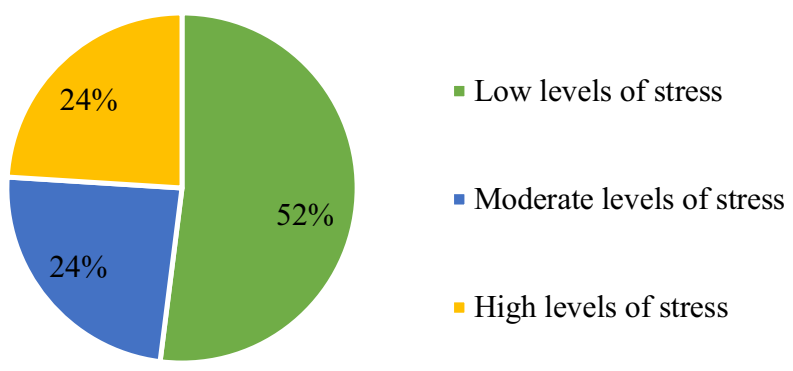

Fig. 1. Levels of stress severity.

More than $60 \%$ of respondents experience a decrease in motivation for professional activity during the transition to working remotely (Fig. 2).

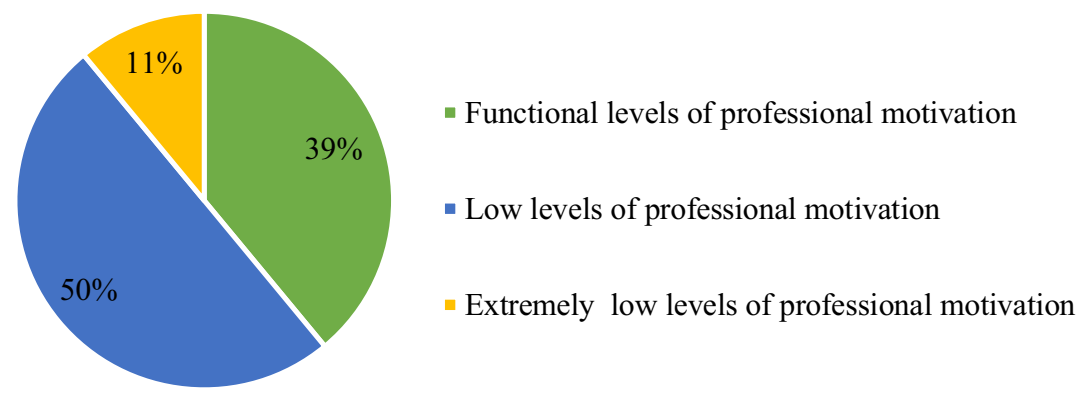

Fig. 2. Level of severity of decrease in motivation for professional activity. 
Comparative analysis of the control and experimental groups showed that university teachers have higher levels of professional motivation and less often complain of feeling unwell and of a decrease in cognitive functions (Fig.3).

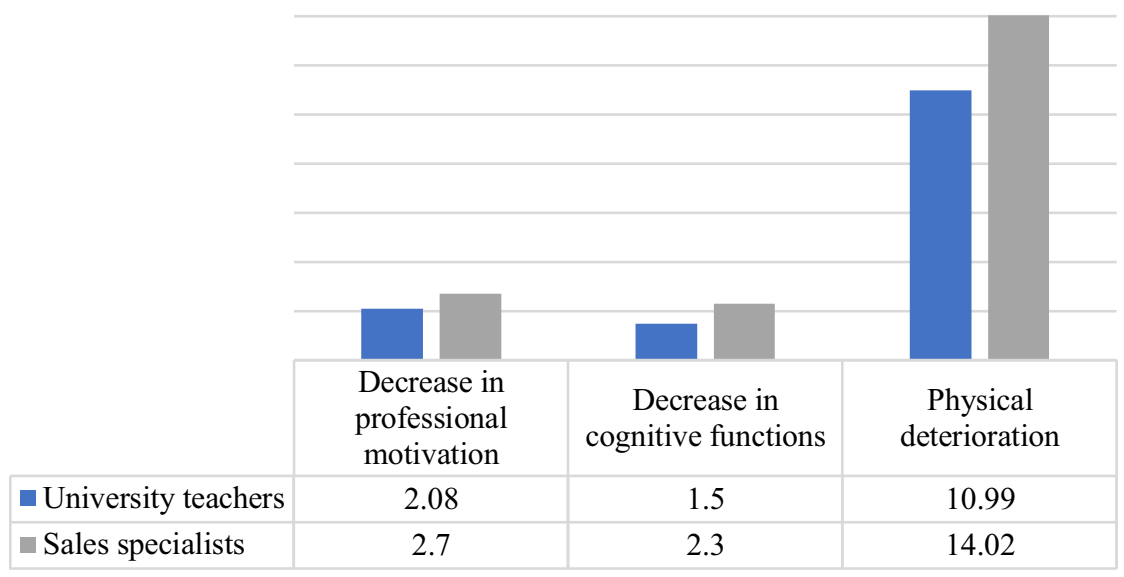

Fig. 3. Comparative analysis of the control and experimental groups $(\mathrm{p}<0.05)$.

For additional control of external variables, we also analyzed the differences for all the measured dependent variables between the groups of respondents who have small children living with them $(n=93)$ and those who do not have small children (or have children over 18 years old; $n=60$ ). As a result, no differences were found in these subgroups, which makes it possible to exclude the influence of this factor on stress levels and the severity of career maladjustment.

Clustering the experimental groups (university teachers) by more stable personality traits (K-means clustering) enabled us to determine changes in dynamic characteristics during the COVID-19 pandemic. We identified 3 clusters with the maximum between-cluster variation in measured parameters. Cluster 1 consisted of 59 individual participants (21 men, 38 women; mean age $=47.3$ ). Cluster 2 consisted of 23 individual participants $(9$ men, 14 women; mean age $=41.2$ ), Cluster 3 consisted of 37 individual participants ( 26 men, 11 women; mean age $=43.8$ ).

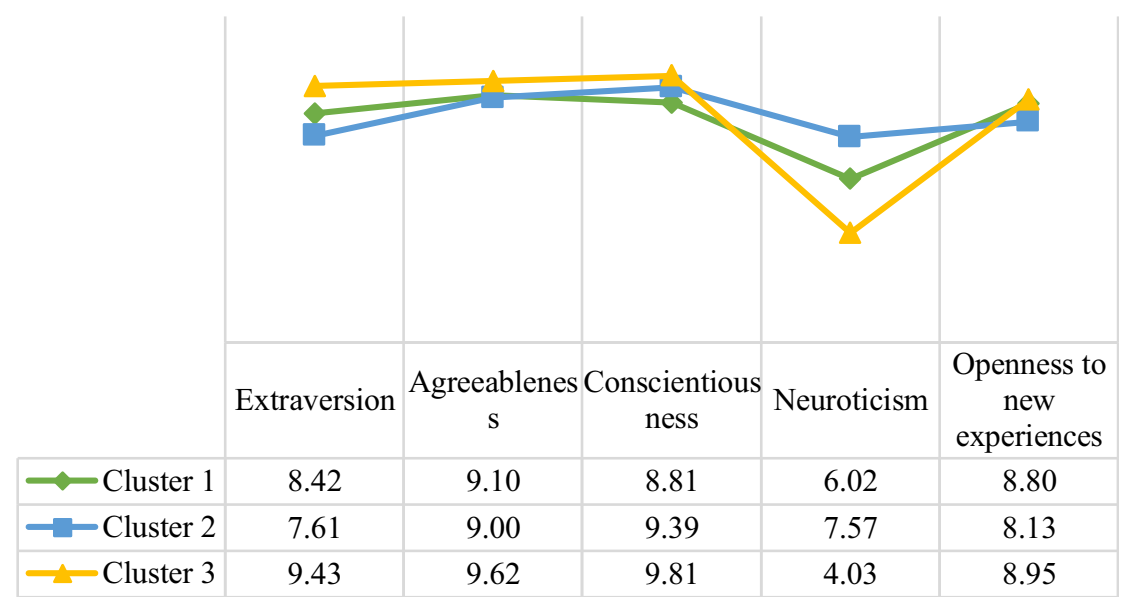

Fig. 4. Cluster analysis results: the scales of the B-10 questionnaire (means). 
The data suggest that the levels of extraversion $(\mathrm{F}=6.37$; signif. $=0.002)$ and neuroticism $(\mathrm{F}=26.31$; signif. $=0.001)$ significantly differ between the selected groups. The differences between the clusters do not reach the level of statistical significance (signif. $>0.050$ ) for the scores of the agreeableness, conscientiousness, and openness scales (Fig. 4).

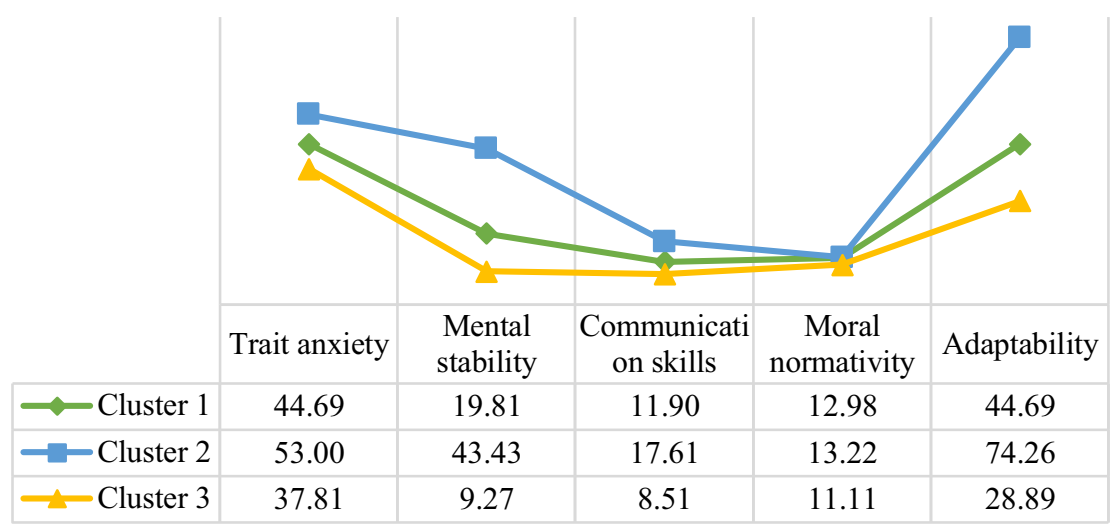

Fig. 5. Cluster analysis results: trait anxiety (Spielberger-Khanin test), adaptive potential, and adaptiveness (MPQ-A) means.

Furthermore, we found significant differences in the levels of trait anxiety $(\mathrm{F}=58.70$; signif. $=0.001)$, mental stability $(\mathrm{F}=196.33$; signif. $=0.001)$, communication skills $(\mathrm{F}=$ 42.59 ; signif. $=0.001)$, moral normativity $(\mathrm{F}=4.29$; signif. $=0.015)$, and general adaptiveness $(\mathrm{F}=193.25$; signif. $=0.001)($ Fig. 5$)$.

The data from Fig. 4 and Fig. 5 suggest that most teachers from the largest cluster (Cluster 1) show average results for the sample in the measured parameters. The most pronounced differences are observed between Clusters 2 and 3. In the second group (Cluster 2) the scores of the neuroticism, trait anxiety, and adaptiveness scales (mental stability, communication skills, moral normativity) are higher. The mean extraversion score is the lowest in this group. Given the inverse nature of the MPQ-A scales, Cluster 2 may be considered as less adaptive. This group of university teachers showed higher introversion. We may characterize them as more anxious and less confident (probably aggressive and defensive); they have a lower mental stability and do not demonstrate an explicit desire to follow generally accepted rules of morality. The respondents included in the third group (Cluster 3) demonstrated higher extraversion and lower scores in the MPQ-A scales, which enabled us to characterize them as the most adaptive, stable, and sociable. This group showed the most pronounced desire to adhere to generally accepted moral norms of behavior. They can quickly develop new behavioral strategies under changing conditions.

Table 1 shows the differences in dynamic psychological characteristics between the clusters.

Table 1. Differences in the severity of components of career maladjustment and coping strategies (H $=$ Kruskal-Wallis H-test (one-way ANOVA on ranks). $\mathrm{p}=$ probability value).

\begin{tabular}{|c|c|c|c|c|c|}
\hline \multirow[t]{2}{*}{ Variables } & \multirow{2}{*}{$\begin{array}{c}\text { Cluster } 1 \\
\mathbf{n}=\mathbf{5 9}\end{array}$} & \multirow{2}{*}{$\begin{array}{c}\text { Cluster } 2 \\
n=23\end{array}$} & \multirow{2}{*}{$\begin{array}{c}\text { Cluster } 3 \\
\mathbf{n}=\mathbf{3 7}\end{array}$} & \multicolumn{2}{|c|}{$\begin{array}{l}\text { The significance } \\
\text { of differences }\end{array}$} \\
\hline & & & & $\mathbf{H}$ & $\mathbf{p}$ \\
\hline \multicolumn{6}{|c|}{ Levels of stress and unmotivated anxiety } \\
\hline Stress levels & 63.34 & 90.33 & 35.82 & 37.813 & 0.001 \\
\hline Unmotivated anxiety & 65.94 & 82.57 & 36.50 & 29.648 & 0.001 \\
\hline
\end{tabular}




\begin{tabular}{|l|c|c|c|c|c|}
\hline $\begin{array}{l}\text { Decrease in professional } \\
\text { motivation }\end{array}$ & 57.44 & 81.87 & 50.49 & 12.841 & 0.001 \\
\hline Emotional shifts in cognitive & 60.69 & 102.07 & 32.76 & 58.873 & 0.001 \\
\hline $\begin{array}{l}\text { Decrease } \\
\text { functions }\end{array}$ & 58.95 & 88.26 & 44.11 & 25.102 & 0.001 \\
\hline Decrease in overall activity & 58.04 & 93.28 & 42.43 & 32.186 & 0.001 \\
\hline Feeling fatigue & 63.12 & 96.50 & 32.34 & 51.037 & 0.001 \\
\hline $\begin{array}{l}\text { Deterioration in the general } \\
\text { sense of well-being }\end{array}$ & 61.70 & 102.41 & 30.92 & 61.610 & 0.001 \\
\hline & Coping strategies \\
\hline Emotion-oriented coping & 63.44 & 91.63 & 34.85 & 39.692 & 0.001 \\
\hline Avoidance-oriented coping & 58.97 & 43.09 & 72.15 & 10.199 & 0.006 \\
\hline Social diversion & 54.77 & 43.48 & 78.61 & 17.591 & 0.001 \\
\hline
\end{tabular}

The data suggest that less adaptive respondents (Cluster 2) have higher levels of stress and are more prone to display unmotivated anxiety (Table 1). This group demonstrates the highest level of career maladjustment. Such maladjustment manifests itself in decreased professional motivation and overall activity, feeling of inefficiency of the processes of attention and memory, mood dysphoria with irritability and apathy, as well as deterioration in the general sense of well-being. In addition, the respondents of this group are more inclined to display negative emotions and self-blame; coping with stress manifests itself in openly expressing indignation and complaints. In the more adaptive group (Cluster 1), there are average (moderate) levels of stress, unmotivated anxiety, and components of career maladjustment. At the same time, the dominant coping strategy is also emotion-oriented coping, but its intensity is lower in comparison with the previously discussed group (Cluster 2). Cluster 3 (with the highest levels of adaptiveness) showed the lowest stress levels, unmotivated anxiety, and the severity of career maladjustment. In general, the respondents from this group are more inclined to avoid negative or unpleasant situations and feelings (in the form of social diversion).

The results relating to the severity of psychological discomfort when using the Internet suggest that more than $85 \%$ of the respondents in the experimental group experience moderate or severe discomfort and point out violation in psychological boundaries when using the Internet (Fig. 6).

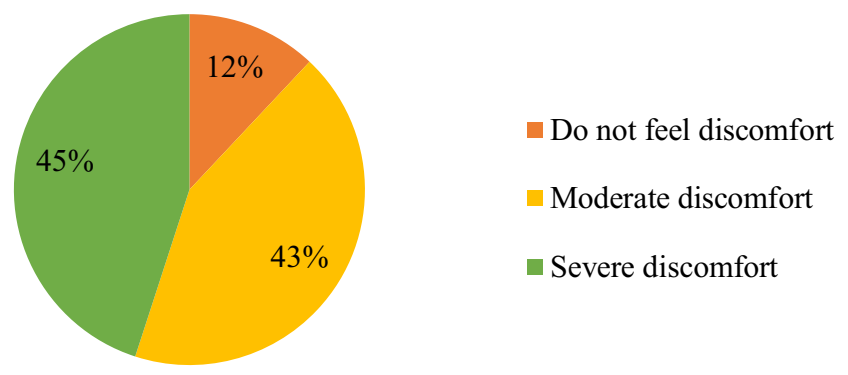

Fig. 6. Changes in psychological boundaries when using the Internet.

To comprehend these results, we analyzed the answers of the respondents to the questions of this test qualitatively. Thus, the majority of university teachers believe that more intensive use of the Internet negatively affects critical thinking and the ability to evaluate the information provided via free Internet searches. Excessive computer use is very timeconsuming and interferes with 'real' daily activities and relationships with family and friends. 
We may assume that the violation of psychological boundaries when using the Internet contributes to a decrease in the feeling of control over time and life events as well as in satisfaction with the work process.

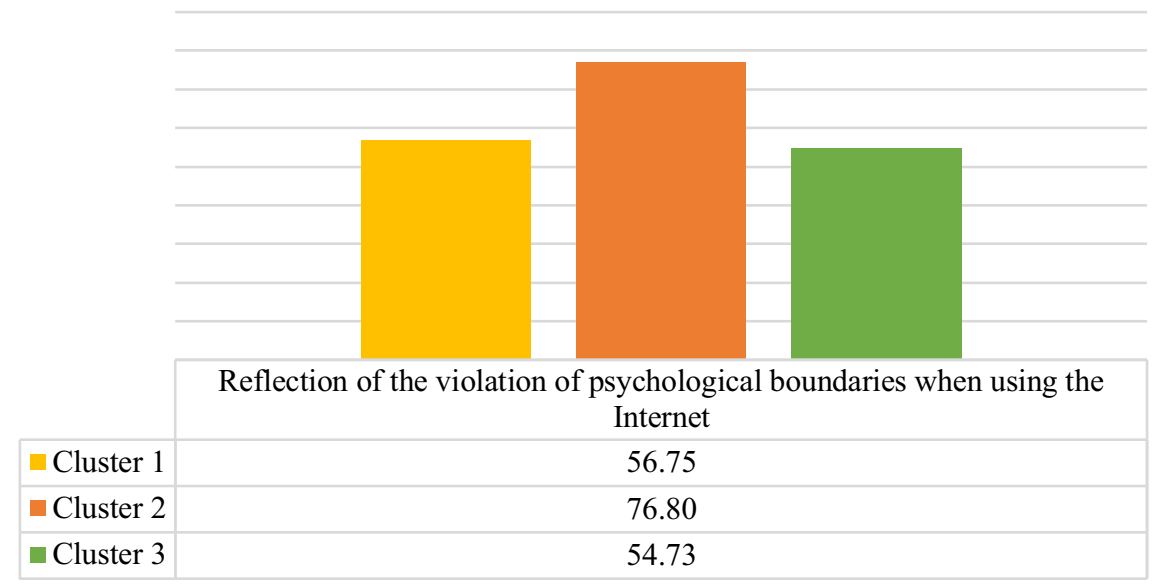

Fig. 7. Cluster analysis results: violation of psychological boundaries when using the Internet.

We also found differences between the groups identified using cluster analysis. The less adaptive group (Cluster 2) is more inclined to experience discomfort when using the Internet (Fig. 7). This result is of special interest because the representatives of this group are, on average, younger.

\section{Discussion}

This study was designed to investigate the stable and dynamic personality traits of university teachers during the transition to distance (online) education caused by the threat of the COVID-19 pandemic.

We analyzed the levels of stress and professional motivation in our sample and can conclude that there is a general trend towards a decrease in professional motivation and an increase in stress levels. These findings are consistent with the results of previous studies on the impact of the COVID-19 pandemic on mental health. Both locally in our country and globally, scientists note that the current situation has a serious impact on psychological wellbeing [17-24].

Previous data suggests that the educational process, mediated by online computer technologies, requires a specific teaching experience [6]. It has been shown that teachers who have such communicative qualities as benevolence, openness, neuroplasticity, stress resistance, and the presence of self-regulation and self-discipline skills are more successful in the implementation of online courses $[8,9,25,26]$. However, the uniqueness of the situation of the forced and widespread transition to distance learning during the period of the COVID-19 pandemic threat causes a lack of research in the psychological consequences, mechanisms of adaptation to the new format, and the factors that determine its success.

The COVID-19 pandemic has disrupted all our lives. Social distancing, fear of contracting the virus, disturbing media content, mortality rate statistics, fear of death and fear of losing loved ones, financial uncertainty, inconsistent information about the severity of the virus, a lot of fake news, anxiety about possible worldwide economic crisis will be experienced in different ways by people with pre-existing personality differences. The proposed division of psychological characteristics into the stable and dynamic personality 
traits was based on traditional ideas about the structure of personality and the Big Five or 5factor model [27].

We identified three clusters with the maximum between-cluster variation in the measured stable personality traits. Clusters 2 and 3 have directly opposite results in terms of extraversion and neuroticism, as well as in terms of the level of trait anxiety, the general indicator of adaptive potential and all its components. Less adaptive in terms of stable personality parameters respondents are more likely to experience stress and more inclined to display higher levels of unmotivated anxiety. They demonstrate a higher level of career maladjustment and subjective discomfort when using the Internet. The preferred coping strategy is to openly complain about work or general negative feelings.

Some researchers provide evidence for the presence of associations among extraversion, neuroticism, and the characteristics of responding to situations of uncertainty and stress in general [22]. Moreover, factors influencing the characteristics of behavior in ambiguous, stressful conditions include the characteristics of teacher-student relationships, gender, age, length of teaching experience, dominant mechanisms of psychological defense, and selfregulation skills [28-34].

There is an idea that the adaptive potential decreases with age and individuals of the older age group find it more difficult to master technical teaching aids and implement work duties remotely $[35,36]$. However, our data indicate that the subjective experience of discomfort when using the Internet is higher in the younger group (the average age is lower than in other groups). They are also more likely to feel a decrease in the efficiency of the processes of attention and memory. In other words, this may mean that the reflection of violation of psychological boundaries in the context of distance learning is likely determined not so much by the age of respondents as by their stable personality traits. At the same time, we should note that the problem of uncertainty remains relevant for all the age groups in some studies [37].

\section{Conclusion}

The findings indicate that during the transition to distance (online) education changes in the dynamic personality characteristics of university teachers are mainly determined by their stable personality traits. The levels of stress, unmotivated anxiety, career maladjustment, preferred coping strategies and reflection of violation of psychological boundaries in the form of discomfort when using the Internet significantly differ in groups with varying degrees of adaptiveness, levels of trait anxiety, neuroticism and extraversion. Despite the fact that older age is often viewed as one of the main factors contributing to adaptation difficulties, the severity of these parameters does not depend on respondents' age or the presence of small children in their families.

In general, the described differences in the dynamic psychological characteristics depending on stable personality traits are consistent with the existing knowledge. At the same time, our results represent their own value and expand the understanding of the current challenges facing the academic community and the impact they have.

\section{References}

1. B. Rockenbach, S. Almagno, International information and library review 32(3/4), 453461 (2000)

2. T.G. Khashchenko, O.N. Zhitchenko, Intergenerational relations: modern discourse and strategic choices in psychological and pedagogical science and practice 1, 86-89 (2020) 
3. M.K. Kabardov, Intergenerational relations: modern discourse and strategic choices in psychological and pedagogical science and practice 1, 29-34 (2020)

4. U.S. Cherdakli, The world of science, culture, education 3(82), 278-281 (2020)

5. N.V. Sidyacheva, L.E. Zotova, Modern high technology 5, 218-225 (2020)

6. A.V. Lubskiy, V.V. Kovalev, Humanities of the South of Russia 9(2), 33-50 (2020)

7. I.V. Ivaniuk, O.V. Ovcharuk, Information Technologies and Learning Tools 77(3), 282$291(2020)$

8. E.V. Brodovskaya, A.Yu. Dombrovskaya, R.V. Pyrma, A.V.Sinyakov, A.A. Azarov, Monitoring of Public Opinion: Economic and Social Changes 1, 228 - 251 (2019)

9. W. Bao, Human Behavior and Emerging Technologies 2(2), 113-115 (2020)

10. R. Varalakshmi, K. Arunachalam, Asian Journal of Psychiatry 51, 102091 (2020)

11. P. Sahu, Cureus 12(4), e 7541 (2020)

12. T.S. Tsener, A.V. Oshkina, International Journal of the Humanities and Natural Sciences 5-3, 170-177 (2020)

13. A.W. Irawan, D. Dwisona, M. Lestari, KONSELI Jurnal Bimbingan dan Konseling (EJournal) 7(1), 53-60 (2020)

14. S.J. Daniel, Education and the COVID-19 pandemic (Prospects, 2020)

15. N.S. Rawat, K.C. Choudhary, Coping Strategies with Stress and Anxiety of Tri-Pillar of the Education System in COVID-19. SSRN, 3596912 (2020)

16. W. Cao, Z. Fang, G. Hou, M. Han, X. Xu, J. Dong, J. Zheng, Psychiatry Research 112934 (2020)

17. P. Hyland, M. Shevlin, O. McBride, J. Murphy, T. Karatzias, R. Bentall, A. Martinez, F. Vallières, Anxiety and depression in the Republic of Ireland during the COVID-19 pandemic. Preprint (2020)

18. J. Torales, M. O’Higgins, J. Castaldelli-Maia, A. Ventriglio, International Journal of Social Psychiatry 31, 1-4 (2020)

19. D.T. Bitan, A. Grossman-Giron, Y. Bloch, Y. Mayer, N. Shiffman, S. Mendlovic, Psychiatry Research 113100 (2020)

20. S. Domínguez-Salas, J. Gómez-Salgado, M. Andrés-Villas, D. Díaz-Milanés, M. Romero-Martín, C. Ruiz-Frutos, Healthcare 8, 190 (2020)

21. D.K. Ahorsu, C.Y. Lin, V. Imani, M. Saffari, M.D. Griffiths, A.H. Pakpour, International Journal of Mental Health and Addiction 1 (2020)

22. M.B. Petzold, A. Bendau, J. Plag, et al., Brain and Behavior 00:e01745 (2020)

23. A. Schimmenti, J. Billieux, V. Starcevic, Clinical Neuropsychiatry 17(2), 41-45 (2020)

24. A.N. Alekhin, Ye.A. Dubinina, Arterial Hypertension 26(3), 312-316 (2020)

25. M.H. Donker, M.C. Erisman, T. van Gog, T. Mainhard, Front. Psychol. 11, 867 (2020)

26. X. Huang, J.C.-K. Lee, A.C. Frenzel, Front. Psychol. 11, 1067 (2020)

27. A.M. Wood, J.S. Maltby, Personality and Individual Differences 46, 443-447 (2009)

28. J.L. Spilt, H.M.Y. Koomen, J.T. Thijs, Educational psychology review 23(4), 457-477 (2011)

29. S.J. Haines, J. Gleeson, P. Kuppens, T. Hollenstein, J. Ciarrochi, I. Labuschagne, et al., Psychol. Sci. 27, 1651-1659 (2016)

30. R. Harmsen, M. Helms-Lorenz, R. Maulana, K. Van Veen, Teach. Teach. 24, 626-643 (2018) 
31. R.E. Olson, J. McKenzie, K.A. Mills, R. Patulny, A. Bellocchi, F. Caristo, Teaching and Teacher Education 80, 128-144 (2019)

32. K. Aldrup, U. Klusmann, O. Lüdtke, R. Göllner, U. Trautwein, Learn. Instruct. 58, 126136 (2018)

33. T. Durr, M.L. Chang, R.L. Carson, "Curbing teacher burnout: the transactional factors of teacher efficacy and emotion management," Teacher Motivation: Theory and Practice (Routledge, Abingdon, 2014)

34. M.M. Keller, M.-L. Chang, E.S. Becker, T. Goetz, A.C. Frenzel, Frontiers in psychology 5, 1442 (2014)

35. A.J. Flint, K.S. Bingham, A. Iaboni, International Psychogeriatrics (2020)

36. V.G. Belov, Y.A. Parfenov, S.A. Parfenov, N.L. Boyar, O.A. Titova, Scientific notes of the P.F. Lesgaft' University 3(157), 349-352 (2018)

37. J. López, G. Perez-Rojo, C. Noriega, I. Carretero, et al, International Psychogeriatrics, $1-6(2020)$ 